\title{
Early Experience with Salvage Robotic-Assisted Radical Prostatectomy in Proton Beam Radiotherapy Failures
}

\author{
Yaşar Bozkurt ${ }^{1}$, Murat $\operatorname{Atar}^{2} \oplus$, Louis L. Pisters ${ }^{3} \oplus$ \\ ${ }^{1}$ Department of Urology, İstinye University, İstanbul, Turkey \\ ${ }^{2}$ Department of Urology, Bower Hospital, Diyarbakır, Turkey \\ ${ }^{3}$ Department of Urology, University of Texas, M.D. Anderson Cancer Center, Houston, Texas, USA
}

\begin{abstract}
Aims: To assess the perioperative and short-term functional and oncologic outcomes of the salvage robot-assisted radical prostatectomy (sRARP), after recurrence following primary proton beam therapy for clinically localized prostate cancer.

Methods: Ten patients undergoing sRARP after failure of the prior definitive proton beam therapy for localized prostate cancer were included. BCR is defined as a prostate-specific antigen (PSA) value of $2.0 \mathrm{ng} / \mathrm{mL}$ greater than the absolute nadir. All of the individuals had a diagnosis of prostate cancer via biopsy after proton beam therapy, with negative findings on magnetic resonance imaging/computer tomography of the pelvis and abdomen, and a bone scan. The sRARP procedure with pelvic lymph node dissection was performed by a single surgeon in all patients.
\end{abstract}

Results: The median age of the cohort at sRARP was 66.8 years, and the mean BMI was $29.2 \mathrm{~kg} / \mathrm{m}^{2}$. The mean duration from proton beam therapy to sRARP was 58.4 months; the mean preoperative PSA level was $5.5 \mathrm{ng} / \mathrm{mL}$, the mean operative time was 230 minutes, and the approximate blood loss was $745 \mathrm{~mL}$. Anastomotic leakage occurred in half of the individuals, and bladder neck contracture developed in 6 patients. For 8 patients, the continence results within 6 months followup were available. Overall, 24 complications occurred in 9 patients. At follow-up in the 32 nd month, the overall survival rate was $80 \%$, and the BCR-free survival rate was $90 \%$.

Conclusion: sRARP after proton beam therapy is an applicable procedure, but has a high risk of serious complications.

\section{INTRODUCTION}

For patients suffering from localized prostate cancer (PCA), there are various options for curative treatment, such as brachytherapy (BT), external-beam radiotherapy (EBRT), and radical prostatectomy (RP). Indeed, radiation therapy (RT) is widely used to treat localized PCA., ${ }^{1,2}$ Following RT, 72\% of the patients who had biochemical relapse and were clinically metastasis-free had biopsyproven local recurrence. ${ }^{3}$ High PSA levels and cancer, detected on biopsy 2 years subsequent to the RT, were defined as the true local recurrence of the disease. Patients who experience this situation can be candidates for salvage RP. The options for salvage treatment include cryotherapy, high-intensity focused ultrasound (HIFU), salvage brachytherapy, and salvage radical prostatectomy (sRP). On the other hand, salvage therapies lack an ideal treatment protocol due to the shortage of high-quality data, undesirable side effects of treatments, and inadequate contribution to survival rates. ${ }^{4,5}$
Robot-assisted radical prostatectomy (RARP) makes difficult urological surgeries easier, safer, and more acceptable to both the surgeon and the patients. RARP provides the most improved visualization of the surgical area and improved instrument control, when compared with other techniques. Thus, it can theoretically overcome the major constrictions of sRP surgery, and improve the oncologic and functional outcomes. ${ }^{6}$ Until now, there have been few salvage robot-assisted laparoscopic prostatectomy (sRARP) series. ${ }^{7-10}$ The studies above suggest that sRARP is applicable for patients with recurrent PCA. However, previously performed RT makes SRP a technically challenging procedure, and the complication rate depends on the previously achieved radiation dose.

Currently, three-dimensional conformal radiotherapy (3D-CRT), intensity-modulated radiotherapy (IMRT), and proton beam therapy (PBT) are the 3 kinds of RT that are commonly used for localized PCA. ${ }^{11}$ With their minimal toxicity to surrounding healthy tissues, IMRT and PBT are enhanced forms of RT which can

Corresponding author: Yaşar Bozkurt, Department of Urology, İstinye University, İstanbul, Turkey

e-mail: dryasarbozkurt@hotmail.com

Received: April 25, 2021 Accepted: June 25, $2021 \cdot$ DOI: 10.5152/balkanmedj.2021.21174

Available at www.balkanmedicaljournal.org

ORCID iDs of the authors: Y.B. 0000-0003-3916-6625; M.A. 0000-0003-1659-8134; L.L.P. 0000-0002-9226-6062.

Cite this article as:

Bozkurt Y, Atar M, L. Pisters L. Early experience with salvage robotic-assisted radical prostatectomy in proton beam radiotherapy failures. Balkan Med J. 2021;38(5):310-315.

Copyright@Author(s) - Available online at http://balkanmedicaljournal.org/ 
achieve radiation dose escalation. ${ }^{12}$ It has been proven by several studies that an increased dosage of RT has a positive impact on the biochemical recurrence (BCR) rates, distant metastasis, and local disease progression. However, a great number of these patients may ultimately encounter a BCR and recurrence..$^{5,13}$

In a retrospective study, the authors suggest that PBT is effective and well-tolerated for PCA. ${ }^{14}$ Some studies comparing PBT with IMRT have demonstrated conflicting results; one study suggests that both are equal in terms of rectal dose sparing; however, IMRT is actually superior in terms of bladder sparing. ${ }^{15}$ On the other hand, the other study states a clear advantage of PBT. ${ }^{16}$ Two other reports have asserted that PBT is associated with greater intestine toxicity than IMRT. ${ }^{12,17}$ Owing to its higher toxicity, increased complication rates after sRARP are probable.

The aim of this study is to report the short-term oncological and functional outcomes of sRARP after PBT failure. To our knowledge, this is the first study that discloses the results of patients who solely received PBT before sRARP.

\section{MATERIAL AND METHODS}

After approval by the Institution Review Boards (RCR03-0847), the study was carried out at The University of Texas MD Anderson Cancer Center (MDACC). The study included 10 men undergoing sRARP after failure of prior definitive PBT for localized PCA. For every patient, the following variables were noted: age, race, BMI, total PSA level before PBT and before sRARP, clinical stage, pathological stage, and Gleason scores on biopsy and on sRARP. The inclusion criteria were clinically organ-confined PCA disease after failure of PBT, and having followed-up at least 6 months after sRARP treatment. The exclusion criteria for the study were previous RT for PCA other than PBT, and previous pelvic surgery.

Biochemical failure after PBT has been defined as a PSA value of $2.0 \mathrm{ng} / \mathrm{mL}$ greater than the absolute nadir, according to the American Society for Therapeutic Radiation and Oncology criteria. Every patient underwent a physical examination, serum PSA testing, magnetic resonance imaging (MRI) or computed tomography $(\mathrm{CT})$, and bone scan to exclude distant metastases prior to the surgery. In order to confirm the recurrence of the disease, every patient underwent a prostate biopsy. After the biopsy procedure, patients whose recurrence was proven were considered as candidates for sRARP.

\section{Surgical Technique}

All sRARP operations were carried out by a single surgeon using the six-port Da Vinci ${ }^{\circledR}$ surgical system with either SI or XI platforms. An initial posterior dissection of the seminal vesicles and vas deferens was carried out with a trans-peritoneal approach.

Subsequently, an extended template bilateral pelvic lymph node dissection was performed in all cases. The bladder was then dropped, and the sRARP was completed with sharp dissection along the rectum from both the right and left sides and from base to apex. A 2-0 polydioxanone posterior Rocco suture was placed to anchor the bladder to the sub-urethral tissues. Vesicourethral anastomosis was performed using a combination of 2 or 3 interrupted 4-0 polydioxanone posterior anastomotic sutures followed by a running 2-0 polydioxanone suture for the lateral and anterior aspects of the anastomosis. An anterior bladder closure was carried out in those cases with a wider bladder neck, and this anterior closure performed with a combination of figure of eight 4-0 polydioxanone suture and a running 2-0 polydioxanone suture secured with Lapra-Ty ${ }^{\circledR}$ clips.

According to the Clavien-Dindo classification, post-operative complications were assessed by categorization as early (within 90 days) or late (occurring after 90 days). ${ }^{18}$

\section{Pathologic Analysis}

All biopsies conducted by other institutions were re-read by a single experienced genitourinary pathologist of our hospital. Before sRARP, cancer diagnosis was histologically proven by a TRUSguided needle biopsy. The pathologic staging of the sRARP specimen was performed by the same pathologist.

\section{RESULTS}

One patient was African American, one patient was Asian, and the others were white. Prior to the operation, every patient was continent, and all patients underwent sRARP. The median age of the cohort at sRARP was 66.8 years (57-74), and mean BMI was $29.2 \mathrm{~kg} / \mathrm{m}^{2}$. After PBT, PCA was proven in all patients via a biopsy procedure. The mean PSA level prior to surgery was 5.5 $\mathrm{ng} / \mathrm{ml}$, and the mean time elapsed from PBT to sRARP was 58.4 months. The final report of histopathology demonstrated a tumor stage of T2 in 2, T3a in 3, T3b in 3, and T4 in 2 patients. Extended pelvic lymph node dissection was carried out in every patient at the time of the operation, and 2 patients were confirmed to have positive lymph node results. Table 1 displays characteristic data of the patients.

There was no rectal injury or other major intra operative complication. The operation took 230 minutes, and the blood loss was $745 \mathrm{~mL}$. The median length of hospital stay after sRARP was 3.9 (1-10) days. The median follow-up of patients after sRARP was 31.8 (17-65) months (Table 2). Anastomotic leaks were observed in 5 patients $(50 \%)$. Even though they were managed with prolonged catheterization, a bladder neck contracture eventually occurred in most patients. Bladder neck contractures developed in 6 patients and were managed with direct-vision internal urethrotomy and/or transurethral resection of the bladder neck in 5 patients. Vesicopubic fistula with breakdown of the vesicourethral anastomosis plus bladder neck contracture were observed in 1 patient, and managed with robotic salvage radical cystectomy-ileal conduit plus urethrectomy at the sixth month. All post-operative complications, stricture details, and treatments are listed in Table 3.

According to a preoperative assessment of erectile dysfunction (ED), 7 patients reported that they did not have ED. After the surgery, 5 patients reported about their erectile functions. Unfortunately, 


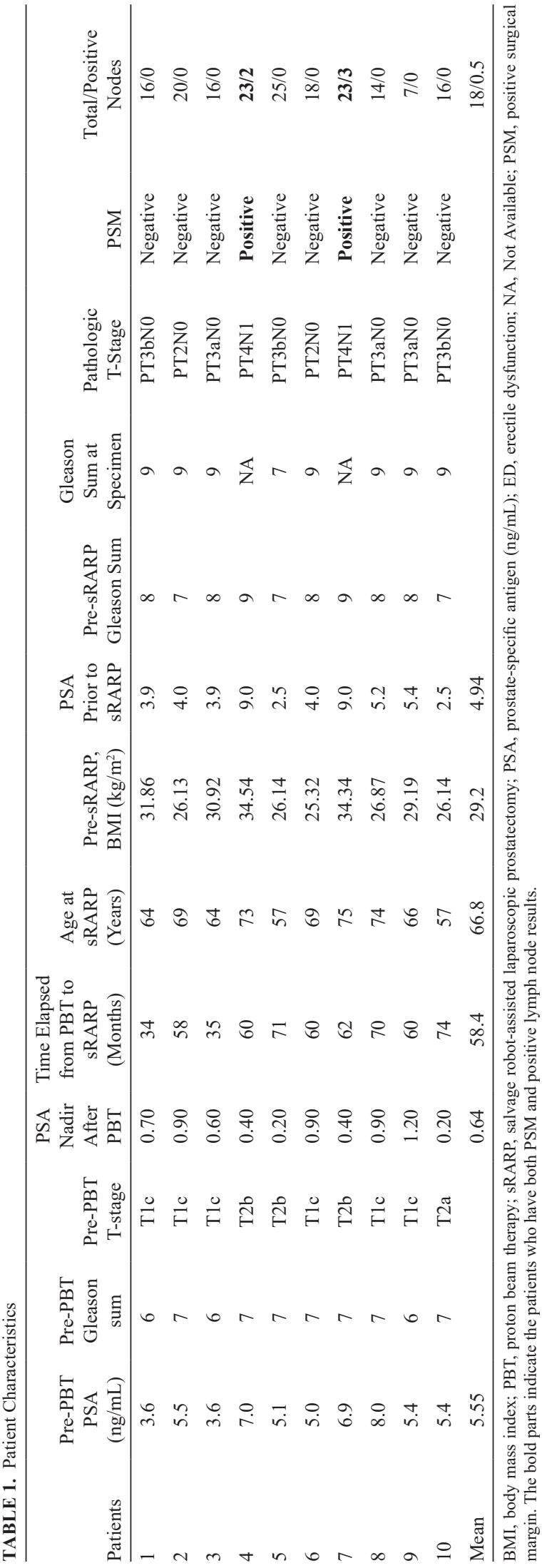

none of them were potent at the sixth month. Tables 2 and 3 demonstrate continence results at a minimum 6 months follow-up for 8 patients. Of these 8 patients, 2 were using $0-1$ pads per day, and 6 of them were using 4 pads per day. When 16 months had passed after the operation, 1 individual had an artificial urethral sphincter implantation surgery. Totally, 24 complications were observed in 9 patients, with $80 \%$ of the patients experiencing multiple complications. Major complications (Clavien Grade 3-4) were seen in 3 patients (Table 3). During the follow-up period, 2 individuals died due to random and natural reasons. At the 32nd month, the BCR-free survival rate was $90 \%$ and the overall survival rate was $80 \%$.

\section{DISCUSSION}

RT causes a wide spectrum of transformations, such as neo-angiogenesis and necrosis in the prostate and the tissues surrounding it. Consequently, tissues decay, and more complications occur after the surgery. Therefore, a locally recurrent PCA after RT can have an aggressive natural history, with poor prognosis. Numerous perioperative, oncologic, and functional outcomes of larger sRARP series after RT modalities have been published. ${ }^{4,5,8,9,19,20}$ When compared to primary RP, an increased risk of complications, such as short-term post-operative events, anastomotic stricture, urinary retention, urinary fistula, rectal injury, abscess, fibrosis, poor wound healing, ED, and urinary incontinence (UI), is related with salvage RP. ${ }^{21-23}$

The number of pads used daily after the surgery was used as a measurement for UI, which is a functional result of salvage therapy after the operation. UI rates at 12 months after salvage surgery were reported to vary from $48 \%$ to $85 \%$. Severe UI rates were estimated as $23 \%$ on average in all articles about salvage surgery, while some studies have even estimated it as $85 \%{ }^{5,24,25}$ Moreover, urinary continence was evaluated as $21-90 \%$ on longer follow ups after salvage surgery. As surgical techniques improve, and patient selection increases, these complications have been seen less frequently in recent studies. ${ }^{5,8,20}$ In the present study, Tables 2and 3 show continence results at a minimum 6 months follow-up for 8 patients. At the end of 6 months, the severe UI rate was higher than $75 \%$.

According to the recent studies, the rate of rectal wall injury has decreased significantly as a result of increased surgical experience and increased quality of vision provided by laparoscopic and robotic cameras.$^{20}$ Another common complication is the occurrence of an anastomotic leak, which is detected in up to $33 \%$ of patients in some studies. ${ }^{20,22}$ The delayed healing process of the anastomosis can be attributed to poor vascularization of the bladder neck and urethral stump, caused by RT. In the present study, there was no rectal injury or other major intraoperative complication, but anastomotic leaks occurred in 5 patients $(50 \%)$. In our study, the anastomotic stricture rate was higher than the literature. This situation may be explained by impaired wound healing after PBT, and the higher toxicity rate of PBT compared with other modalities of RT. 
TABLE 2. Surgical and Pathological Outcomes After Salvage Radical Prostatectomy

\begin{tabular}{|c|c|c|c|c|c|c|c|c|c|}
\hline Patients & $\begin{array}{c}\text { Blood } \\
\text { Loss } \\
(\mathrm{mL})\end{array}$ & $\begin{array}{l}\text { Duration of } \\
\text { Surgery } \\
\text { (Minutes) }\end{array}$ & $\begin{array}{l}\text { Length of } \\
\text { Stay } \\
\text { (Days) }\end{array}$ & $\begin{array}{c}\text { \# Clavien } \\
1-2\end{array}$ & $\begin{array}{c}\text { \# Clavien } \\
3-4\end{array}$ & $\begin{array}{c}\text { Anastomotic } \\
\text { Leakage }\end{array}$ & $\begin{array}{c}\text { Follow-Up } \\
\text { (Months) }\end{array}$ & $\begin{array}{c}\text { Incontinence at } 6 \\
\text { Months (Pads/ } \\
\text { Day) }\end{array}$ & Pre/Post-sRARP ED \\
\hline 1 & 2100 & 268 & 10 & 2 & 0 & No & 64 & 4 & $\mathrm{No} / \mathrm{Yes}$ \\
\hline 2 & 850 & 220 & 2 & 2 & 2 & Yes & 23 & 0 & $\mathrm{No} / \mathrm{NA}$ \\
\hline 3 & 2100 & 263 & 1 & 1 & 0 & No & 64 & 4 & Yes/Yes \\
\hline 4 & 300 & 235 & 6 & 2 & 0 & No & 23 & 4 & Yes/NA \\
\hline 5 & 300 & 243 & 2 & 3 & 0 & Yes & 65 & 1 & No/NA \\
\hline 6 & 850 & 187 & 10 & 3 & 1 & Yes & 18 & NA & No/NA \\
\hline 7 & 300 & 183 & 2 & 3 & 0 & No & 23 & 4 & Yes/Yes \\
\hline 8 & 150 & 247 & 2 & 0 & 0 & No & 20 & 4 & $\mathrm{No} / \mathrm{Yes}$ \\
\hline 9 & 200 & 218 & 3 & 1 & 2 & Yes & 17 & 4 & $\mathrm{No} / \mathrm{Yes}$ \\
\hline 10 & 300 & 243 & 1 & 2 & 0 & Yes & 65 & NA & $\mathrm{No} / \mathrm{NA}$ \\
\hline Mean & 745 & 230.7 & 3.9 & 1.9 & 0.5 & & 31.8 & & \\
\hline
\end{tabular}

Mohler et al. and Seabra et al. ${ }^{24}$ revealed ED rates of $78 \%$ and $74 \%$ at 6 months and 18 months, respectively, after sRP. Recently, Abufarj et al. ${ }^{5}$ found that at least $50 \%$ of men report ED after salvage RP. In a systematic review, Chade et al. disclosed that $50-91 \%$ of patients had ED before salvage treatment, and 80-100\% reported ED after the salvage procedure. ${ }^{4}$ According to preoperative assessment, $70 \%$ of our patients reported that they did not have ED. Unfortunately, after the surgery, none of them were potent at the sixth month.

Salvage treatment for recurrent PCA exposes the previously treated tissues of the urethra and bladder neck to additional forces, compounding the risk for stricture formation. Anastomotic strictures also vary considerably, ranging from $0 \%$ to $55 \%,{ }^{5,21,26}$ because strictures might occur several months after the procedure. This situation indeed requires further investigation, as the majority of the series have a mean follow-up of less than 2 years. In this study, bladder neck contracture developed in 6 patients and was managed with direct-vision internal urethrotomy and/or transurethral resection of the bladder neck.

While oncologic results were considered, a Gleason score of 8 and an extra-capsular extension rate of $50 \%$ have been observed at final pathology in most studies. This shows that radio-recurrent PCA has poor prognosis. ${ }^{20,22}$ Positive surgical margin (PSM) rates are variable, and can be observed in approximately half of the patients in some multicenter series. No evidence of metastatic disease, a post-radiation biopsy confirming PCA, and a sufficiently long life expectancy ( $\geq 10$ years) are the specifications of a good candidate who will benefit from sRP. The preoperative value of PSA $(<10 \mathrm{ng} / \mathrm{mL})$ and Gleason score of the biopsy specimen $(\leq 7)$ should be defined while deciding whether a patient is appropriate for salvage therapy. ${ }^{4}$ In this study, there was no evidence of metastatic disease. The post-radiation biopsy confirmed PCA,

TABLE 3. List of Post-Operative Complications, Stricture Details, and Performed Treatments

\begin{tabular}{|c|c|c|c|}
\hline Patients & List of Complications Within 90 Days & Stricture/BNC & Stricture Detail/Procedures \\
\hline 1 & Wound infection opened (G1). Ileus (G1). & YES & BNC with bladder stones/DVIU at 11 and 15 months \\
\hline 2 & $\begin{array}{l}\text { Anastomotic leak, pelvic hematoma, sepsis, rectovesical } \\
\text { fistula, and colostomy }\end{array}$ & NO & - \\
\hline 3 & Surgical wound infection & YES & Bladder stones/TUR-BN \\
\hline 4 & Dysuria, suprapubic pain, stress, incontinence & NO & - \\
\hline 5 & $\begin{array}{l}\text { Anastomotic leak at } 2 \text { months, pelvic pain, dermatitis in } \\
\text { bilateral groin area }\end{array}$ & NO & - \\
\hline 6 & $\begin{array}{l}\text { Hematuria, drop in hemoglobin, abdominal pain, } \\
\text { anastomotic leakage, sepsis }\end{array}$ & NA & - \\
\hline 7 & Pain, hematuria, dysuria, urgency with bacteriuria & YES & BNC/TUR-BN at 16 months \\
\hline 8 & None & YES & $\mathrm{BNC} / \mathrm{DVIU}$ at 12 months, artificial urinary sphincter at 16 months \\
\hline 9 & $\begin{array}{l}\text { Anastomotic leak, pelvic pain, vesico-pubic fistula with } \\
\text { breakdown of the vesicourethral anastomosis }\end{array}$ & YES & $\begin{array}{l}\text { Fistula Plus BNC/robotic salvage radical cystectomy-ileal conduit, } \\
\text { urethrectomy at sixth months }\end{array}$ \\
\hline 10 & $\begin{array}{l}\text { Anastomotic leak about } 40 \text { days post-op, dermatitis in } \\
\text { groin and scrotum skin }\end{array}$ & NA & - \\
\hline
\end{tabular}

BNC, bladder neck contracture; DVIU, direct-vision internal urethrotomy; TUR, trans urethral resection; BN, bladder neck; G1, grade 1. 
TABLE 4. Perioperative, Oncologic, and Functional Outcomes in Some Salvage Robot-Assisted Laparoscopic Prostatectomy Series After Radiation Therapy Modalities and Present Study

\begin{tabular}{|c|c|c|c|c|c|c|c|c|c|c|c|}
\hline Series & No. & Type of Radiation & $\begin{array}{c}\text { Mean } \\
\text { EBL }\end{array}$ & $\begin{array}{l}\text { Follow-up } \\
\text { (Months) }\end{array}$ & $\begin{array}{l}\text { ORT, } \\
\text { min }\end{array}$ & $\begin{array}{c}\text { Overall } \\
\text { Comp, } n\end{array}$ & PSM, $n$ & LNI, $n$ & Continence & Potenc, $n$ & $\begin{array}{l}\text { BCR During, } \\
\text { Follow-up, } n\end{array}$ \\
\hline Onol et al. ${ }^{9}$ & 94 & $\begin{array}{l}54 \text { XRT, } 23 \text { BT, } 3 \text { PBT, } 14 \\
\text { XRT+BT }\end{array}$ & 106 & 24 & 128 & 24 & $16 / 94$ & 10 & $45 / 94$ & $33 / 94$ & 16 \\
\hline Bates et al. ${ }^{22}$ & 53 & & 120 & 26 & 130 & NA & $10 / 53$ & 14 & $34 / 53$ & $14 / 44$ & 8 \\
\hline Eandi et al. ${ }^{27}$ & 18 & 8 BT, 8 XRT, 2 PBT & 150 & 18 & 156 & 7 & $5 / 18$ & 1 & $6 / 18$ & $0 / 18$ & 6 \\
\hline Yuh et al. ${ }^{28}$ & 51 & $\begin{array}{l}\text { 22BT, 18XRT, 6PBT, 3Cryo, } \\
\text { 1HIFU, 1XRT+BT }\end{array}$ & 175 & 36 & 179 & 24 & $16 / 51$ & 3 & $23 / 51$ & $6 / 13$ & 10 \\
\hline $\begin{array}{l}\text { Kaffenberger } \\
\text { et al. }^{30}\end{array}$ & 34 & $\begin{array}{l}13 \mathrm{BT}, 11 \mathrm{XRT}, \\
6 \mathrm{BT}+\mathrm{XRT}, 4 \mathrm{HIFU}\end{array}$ & NA & 16.1 & 176 & 13 & $9 / 34$ & 0 & $12 / 33$ & $5 / 33$ & 6 \\
\hline Present study & 10 & $10 \mathrm{PBT}$ & 745 & 31.8 & 231 & 24 & $2 / 10$ & 2 & $7 / 8$ & $0 / 3$ & 1 \\
\hline
\end{tabular}

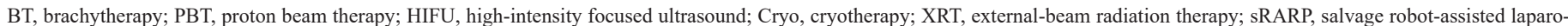

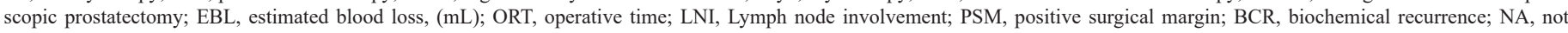
available.

and pre-surgical PSA was $<10 \mathrm{ng} / \mathrm{mL}$ in all patients. The Gleason sum score of the post-radiation biopsy was 7 in 3 patients, 8 in 5 patients, and 9 in 2 patients. The surgical margin was negative in 8 patients, while 2 patients had PSM and positive lymph nodes. The Gleason score of patients who had PSM was 9 before sRARP. Therefore, the Gleason score can be considered as an important prognostic factor for outcomes of sRARP after RT.

The perioperative, oncologic, and functional outcomes of some large sRARP series after RT modalities are listed in Table 4. Eandi et al. ${ }^{27}$ have published their study about sRARP including 18 patients, in which the median operative time, EBL, and length of stay were, respectively, 2.6 hours, $150 \mathrm{~mL}$, and 2 days. Yuh et al. ${ }^{28}$ described their series of sRARP in 51 patients. In this study, the median age of individuals was 68 , while the median time from first therapy to sRARP was 68 months. The estimated amount of blood loss was $175 \mathrm{~mL}$, and the mean duration of the operation was 179 minutes. According to the final pathology results, 50\% of the patients had extra-capsular involvement, and $31 \%$ of the patients had the PSMs. The writers also reported that the BCR rate or progression-free survival rate was $57 \%$, after a median follow-up of 36 months. In this series, significant complications (47\%) were reported, including incontinence and ED. The potency rate was reported, and it shows that only $23 \%$ of the patients were potent preoperatively. Moreover, the rate of spontaneous return of urinary continence was reported in 23 patients $(45 \%)$ with a median time of 6 months. In the present study, the mean EBL was $745 \mathrm{~mL}$, and the rate of the overall number of complications was higher than in previous studies. Major complications (Grade 3-4) occurred in 3 patients.

The relative efficiency of PBT was raised to 1.1 in a study ${ }^{29}$ in which the biological efficiency is estimated to be a little higher than that of high-voltage X-ray/Cobalt-60. Although it may increase toxicity level, this $10 \%$ increase of biological effectiveness might result in better tumor control. Thus, the higher complication rates in our results, including urine leakage, bladder neck contracture, and incontinence, may be explained by the higher toxicity rate of PBT prior to surgery. However, in order to make this precise conclusion, a randomized control study is necessary. In contrast to other studies in which different RT modalities were conducted before salvage surgery, our study consists of patients who received only PBT before the surgery.

This study has several limitations. Firstly, the study is retrospective. Secondly, the sample size is limited. Thirdly, it is not a comparative study including patients who received other types of RT. Lastly, the short follow-up period impairs our ability to assess precise final oncological and functional results. Despite these limitations, our study is valuable for providing the results of sRARP in isolated groups of patients receiving PBT before surgery.

sRARP after PBT has a high complication rate. Although our sample size is small, it can be said that the higher rate of complications in our results may be explained by the higher toxicity rate of PBT prior to surgery. Additionally, further prospective and randomized controlled studies are required to validate our findings.

Ethics Committee Approval: This study was approved by the Institutional Review Board (RCR03-0847) of MD Anderson Cancer Center.

Patient Consent for Publication: This is a retrospective cross-sectional study for which no formal consent is required.

Data-sharing Statement: The authors confirm that all data supporting the findings of this study are available within the article.

Author Contributions: Concept - L.L.P.; Design - Y.B., L.L.P.; Supervision - L.L.P.; Materials - Y.B.; Data Collection and/or Processing - Y.B., L.L.P.; Analysis and/or Interpretation - L.L.P., M.A.; Literature Review - M.A.; Writing - Y.B., L.L.P., M.A.; Critical Review - L.L.P., M.A.

Conflict of Interest: The authors declare that no conflicts of interest exist.

Funding: The authors declared that this study has received no financial support.

\section{REFERENCES}

1. Jang JW, Drumm MR, Efstathiou JA, et al. Long-term quality of life after definitive treatment for prostate cancer: patient-reported outcomes in the second posttreatment decade. Cancer Med. 2017;6:1827-1836. [CrossRef]

2. Burt LM, Shrieve DC, Tward JD. Factors influencing prostate cancer patterns of care: an analysis of treatment variation using the SEER database. Adv Radiat Oncol. 2018;3:170-180. [CrossRef] 
3. Agarwal PK, Sadetsky N, Konety BR, et al. Treatment failure after primary and salvage therapy for prostate cancer: likelihood, patterns of care, and outcomes. Cancer. 2008;112:307-314. [CrossRef]

4. Chade DC, Eastham J, Graefen M, et al. Cancer control and functional outcomes of salvage radical prostatectomy for radiation-recurrent prostate cancer: a systematic review of the literature. Eur Urol. 2012;61:961-971. [CrossRef]

5. Abufaraj M, Siyam A, Ali MR, et al. Functional outcomes after local salvage therapies for radiation-recurrent prostate cancer patients: a systematic review. Cancers (Basel). 2021;13. [CrossRef]

6. Coughlin GD, Yaxley JW, Chambers SK, et al. Robot-assisted laparoscopic prostatectomy versus open radical retropubic prostatectomy: 24-month outcomes from a randomised controlled study. Lancet Oncol. 2018;19:1051-1060. [CrossRef]

7. Acar O, Esen T. Robotic radical prostatectomy in patients with previous prostate surgery and radiotherapy. Prostate Cancer. 2014;2014:367675. [CrossRef]

8. Gontero P, Marra G, Alessio P, et al. Salvage radical prostatectomy for recurrent prostate cancer: morbidity and functional outcomes from a large multicenter series of open versus robotic approaches. J Urol. 2019;202:725-731. [CrossRef]

9. Onol FF, Bhat S, Moschovas M, et al. Comparison of outcomes of salvage robotassisted laparoscopic prostatectomy for post-primary radiation vs focal therapy. BJU Int. 2020;125:103-111. [CrossRef]

10. Kenney PA, Nawaf CB, Mustafa M, et al. Robotic-assisted laparoscopic versus open salvage radical prostatectomy following radiotherapy. Can J Urol. 2016;23: 8271-8277.

11. Kamran SC, D'Amico AV. Radiation therapy for prostate cancer. Hematol Oncol Clin North Am. 2020;34:45-69. [CrossRef]

12. Sheets $\mathrm{NC}$, Goldin GH, Meyer AM, et al. Intensity-modulated radiation therapy, proton therapy, or conformal radiation therapy and morbidity and disease control in localized prostate cancer. JAMA. 2012;307:1611-1620. [CrossRef]

13. Dearnaley DP, Jovic G, Syndikus I, et al. Escalated-dose versus control-dose conformal radiotherapy for prostate cancer: long-term results from the MRC RT01 randomised controlled trial. Lancet Oncol. 2014;15:464-473. [CrossRef]

14. Iwata $\mathrm{H}$, Ishikawa $\mathrm{H}$, Takagi $\mathrm{M}$, et al. Long-term outcomes of proton therapy for prostate cancer in japan: a multi-institutional survey of the Japanese radiation oncology study group. Cancer Med. 2018;7:677-689. [CrossRef]

15. Trofimov A, Nguyen PL, Coen JJ, et al. Radiotherapy treatment of early-stage prostate cancer with IMRT and protons: a treatment planning comparison. Int J Radiat Oncol Biol Phys. 2007;69:444-453. [CrossRef]

16. Vargas C, Fryer A, Mahajan C, et al. Dose-volume comparison of proton therapy and intensity-modulated radiotherapy for prostate cancer. Int J Radiat Oncol Biol Phys. 2008;70:744-751. [CrossRef]
17. Rossi CJ, Sung Kim Jr Re, Shunhua S, et al. Late gastrointestinal toxicities following radiation therapy for prostate cancer. Eur Urol. 2011;60:908-916.

18. Dindo D, Hahnloser D, Clavien PA. Quality assessment in surgery: riding a lame horse. Ann Surg. 2010;251:766-771. [CrossRef]

19. Zargar H, Lamb AD, Rocco B, et al. Salvage robotic prostatectomy for radio recurrent prostate cancer: technical challenges and outcome analysis. Minerva Urol Nefrol. 2017;69:26-37. [CrossRef]

20. Calleris G, Marra G, Dalmasso E, et al. Is it worth to perform salvage radical prostatectomy for radio-recurrent prostate cancer? A literature review. World J Urol. 2019;37:1469-1483. [CrossRef]

21. Artibani W, Porcaro AB, De Marco V, Cerruto MA, Siracusano S. Management of biochemical recurrence after primary curative treatment for prostate cancer: a review. Urol Int. 2018;100:251-262. [CrossRef]

22. Bates AS, Samavedi S, Kumar A, et al. Salvage robot-assisted radical prostatectomy: a propensity matched study of perioperative, oncological and functional outcomes. Eur J Surg Oncol. 2015;41:1540-1546. [CrossRef]

23. Gotto GT, Yunis LH, Vora K, et al. Impact of prior prostate radiation on complications after radical prostatectomy. $J$ Urol. 2010;184:136-142. [CrossRef]

24. Mohler JL, Halabi S, Ryan ST, et al. Management of recurrent prostate cancer after radiotherapy: long-term results from CALGB 9687 (Alliance), a prospective multiinstitutional salvage prostatectomy series. Prostate Cancer Prostatic Dis. 2019;22:309-316. [CrossRef]

25. Devos B, Al Hajj Obeid W, Andrianne C, et al. Salvage high-intensity focused ultrasound versus salvage radical prostatectomy for radiation-recurrent prostate cancer: a comparative study of oncological, functional, and toxicity outcomes. World J Urol. 2019;37:1507-1515. [CrossRef]

26. Golbari NM, Katz AE. Salvage therapy options for local prostate cancer recurrence after primary radiotherapy: a literature review. Curr Urol Rep. 2017;18:63. [CrossRef]

27. Eandi JA, Link BA, Nelson RA, et al. Robotic assisted laparoscopic salvage prostatectomy for radiation resistant prostate cancer. J Urol. 2010;183:133-137. [CrossRef]

28. Yuh B, Ruel N, Muldrew S, et al. Complications and outcomes of salvage robotassisted radical prostatectomy: a single-institution experience. BJU Int. 2014;113: 769-776. [CrossRef]

29. Paganetti H, Niemierko A, Ancukiewicz M, et al. Relative biological effectiveness (RBE) values for proton beam therapy. Int J Radiat Oncol Biol Phys. 2002;53: 407-421. [CrossRef]

30. Kaffenberger SD, Keegan KA, Bansal NK, et al. Salvage robotic assisted laparoscopic radical prostatectomy: a single institution, 5-year experience. J Urol. 2013;189: 507-513. [CrossRef] 